\title{
Tracing the Incorporated Fluorine in Spray Deposited Nanocrystalline Tin Oxide Thin Film
}

\author{
Hassan Hassan AFIFY1, Hamdia Abd-El Hamid ZAYD', \\ Salama Edward DEMIAN ${ }^{1}$ and Shimaa Ahmed ALY ${ }^{1}$ \\ 1-National Research Centre -Dokki Giza EGYPT \\ 2-College for Women Ain-Shams University Cairo EGYPT \\ ahassanafify@ymail.com bhamdia44@yahoo.com
}

\begin{abstract}
Pure and fluorine incorporated tin oxide thin films are synthesized using a cost-effective spray pyrolysis technique. The dependence of the morphology, structure, optical properties, and sheet resistance of the prepared $\mathrm{SnO}_{2}: \mathrm{F}$ films, on the concentration of fluorine in spray solution are reported. The $2 D \&$ $3 D$ AFM images show observable changes in grain size and shape. The XRD patterns are considered as a good monitor for fluorine in $\mathrm{SnO}_{2}$ lattice. The crystallite size is found to be in the range 18 to $40 \mathrm{~nm}$ as calculated from XRD patterns. The energy gap of the pure sample is larger than that reported for samples having larger crystallite size, in micron and submicron ranges. The plasma frequencies $\omega_{p}$ of the $F$ incorporated samples exhibit blue shift due to increase in carrier concentration. The electron concentration, mobility, mean free path and Fermi energy are calculated from the experimentally determined $\omega_{p}$. Sheet resistance is measured and correlated with the reflectance at $\lambda=$ $2500 \mathrm{~nm}$. The figure of merit and performance coefficient are estimated. It is found that prepared $\mathrm{SnO}_{2}$ : F could be considered as a promising candidate for solar energy applications and optoelectronic devices.
\end{abstract}

\section{Introduction:}

Thin films of transparent conducting oxide (TCO) are characterized by possessing high electrical conductivity and high transparency in the visible region. Moreover, they are very efficient in reflecting broad band infrared heat radiation. These properties allow them to be excellent candidates as heat mirrors and for optoelectronic device applications. To further improve their performance, the films are doped with a higher valence cation [1] or a lower valence anion [2]. Tin oxide $\left(\mathrm{SnO}_{2}\right)$ films are promising for solar thermal energy conservation due to their environmental stability, and anti acid and base corrosion. The incorporation of fluorine in $\mathrm{SnO}_{2}$ films enhances the electrical conductivity without appreciable decrease in the optical transmittance [3]. Due to the wide applications of $\mathrm{SnO}_{2}: \mathrm{F}$ films with optimum conductivity and light 
transmission, their production with low cost technique becomes a goal of great interest.

A large variety of techniques have been developed for $\mathrm{SnO}_{2}: \mathrm{F}$ thin film deposition. Spray pyrolysis is one of the most convenient techniques because of its simple, inexpensive experimental arrangement, high growth rate and wide possibility of varying the film characteristics by changing the composition of the starting solution and the spray pyrolysis parameters. $\mathrm{SnO}_{2}$ : F films had been extensively studied, the reported results are diverse [4 -6]. The likelihood to this diversity may be due to the great dependence of film properties on the spray pyrolysis parameters which have high degree of freedom.

The aim of the present study is to produce highly conducting and highly transmitting $\mathrm{SnO}_{2}$ : F films with high figure of merit and high performance coefficient as TCO, by a low cost technique. Also, the structural, optical and sheet resistance will be studied, focusing on tracing the process by which the incorporated fluorine atom was accommodated in $\mathrm{SnO}_{2}$ lattice, as the reported data in literature are not definitely clear.

\section{Experimental Details:}

Pure and F doped (incorporated) tin oxide films are prepared by the spray pyrolysis technique. The used spray set-up was described elsewhere [7] and shown in Fig. (1). It consists of a locally made glass nozzle, peristaltic pump, air compressor, flow meter, and hot plate heater provided with controller circuit to adjust its temperature via $\mathrm{Cu} / \mathrm{Cu}$ constantan thermocouple. The substrate on heater surface and the spraying nozzle are mounted in a glass enclosure to maintain temperature stability. The spray system is placed in fumed cupboard provided with a fan to remove the byproduct gases.

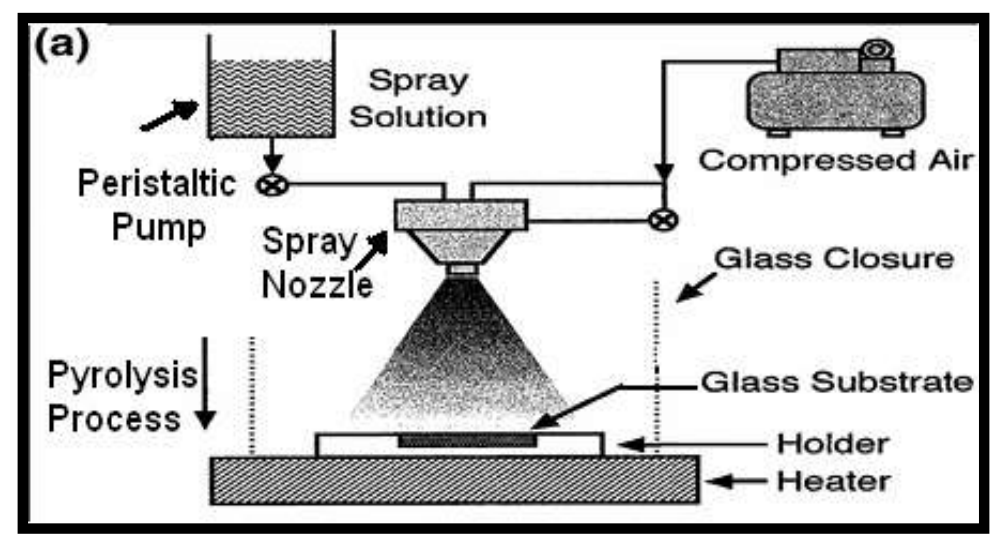

Fig. (1): Schematic Diagram of the Spray System. 
The mother $0.8 \mathrm{M}$ spray solution is prepared by dissolving $14 \mathrm{gm}$ of $\mathrm{SnCl}_{4} .5 \mathrm{H}_{2} \mathrm{O}$ in $50 \mathrm{ml}$ ethyl alcohol. The $0.8 \mathrm{M}$ dopant solution is prepared by dissolving $2 \mathrm{gm}$ of $\mathrm{NH}_{4} \mathrm{~F}$ in $50 \mathrm{ml}$ of bi-distilled water. The doped (incorporated) samples are prepared from the spray solution composed of $50 \mathrm{ml}$ of mother solution and added different volumes of dopant solution ranging from $1 \mathrm{ml}$ up to $12.5 \mathrm{ml}$. The added volumes of dopant solution are considered as the concentration ratio of the dopant. The spray parameters were varied alternatively until a film with apparent homogenous features was obtained. The spray parameters are then kept at their optimum values. The spray time $4 \mathrm{~min}$ and the substrate temperature $\left(425^{\circ} \mathrm{C}\right)$ are kept constant. The structure information are obtained from the X-ray diffraction patterns. The specular transmittance and reflectance of the investigated samples are measured by double beam spectrophotometer. The blank glass substrate is used as the reference. The sheet resistance is measured for the investigated samples by the four probe method. The film topography is elucidated by AFM.

\section{Results and Discussion:}

\subsection{Structural Properties:}

The obtained XRD patterns for the investigated pure and incorporated samples are shown in Fig.(2). The XRD pattern of the pure sample Fig.(2-a) shows six peaks at $2 \theta$ equal to $26.58,33.58,38.18,54.78,61.78$ and 66.28 which correspond to the (110), (101), (200), (211), (310) and (301) planes respectively. These peaks are in accordance with that reported in JCPDS file number (41-1445) for pure $\mathrm{SnO}_{2}$.

The XRD patterns reveal that the samples are polycrystalline single phase of tin oxide $\left(\mathrm{SnO}_{2}\right)$ having tetragonal (cassiterite) structure, corresponding to the space group $\left(\mathrm{D}_{4 \mathrm{~h}}{ }^{14} \mathrm{P}_{2}{ }^{4} / \mathrm{mnm}\right)$. The lattice parameters a \& $\mathrm{c}$ are calculated and found to be $\mathrm{a}=4.71 \mathrm{~A}^{\circ}$ and $\mathrm{c}=3.179 \mathrm{~A}^{\circ}$. These values are consistant with (JCPDS) data (41-1445) and published articles [8]. The intensity of the (200) plane is too high compared with the other peaks' intensities which indicates that the plane (200) is the preferred growth orientation. The structure factor for (110) \& (200) which appeared in pure tin oxide as function of occupation probability of interstitial tin is calculated by Agashe [8]. It is found that as the tin concentration increases, tin atoms ( $\mathrm{Sn}$ ) go gradually to interstitial sites, so $|\mathrm{F}(110)|^{2}$ decreases whereas $|\mathrm{F}(200)|^{2}$ increases. Based on this result the observed high intensity of (200) accompanied with very low intensity of (110) in the investigated pure samples Fig.(2-a) could be considered as a result of the excess Sn atoms in interstitial positions. This conjecture is supported by the low values of the measured sheet resistance (200 
$\Omega / \square$ ) and reasonable absorption in NIR region Fig.(6). The low intensity of (101) \& (211) peaks in XRD of pure sample point out that there are oxygen vacancies [9,10]. This indicates that the investigated pure sample is nonstoichiometric tin oxide with predominant $\mathrm{Sn}$ interstitial atoms accompanied with oxygen vacancies. The general features of the peaks are broad and have low intensity. This may be due to the nanosize of the crystallites forming the film.

Significant change in both peak intensity and preferred growth orientation without observable change in peak position in XRD pattern for the investigated $\mathrm{SnO}_{2}$ : $\mathrm{F}$ samples are observed. This observation is recorded in some of the published articles $[4,11$, and 12]. The most probable explanation for that is structural changes in pure $\mathrm{SnO}_{2}$ due to fluorine doping is expected to be very small or non existent due to the fact that the ionic radii of fluorine and oxygen are close. Also, the energy of the Sn-F bond $\sim 112 \mathrm{kcal} / \mathrm{mole}$ is comparable to that of the $\mathrm{Sn}-\mathrm{O}$ bond $\sim 130 \mathrm{kcal} / \mathrm{mole}$ [13].

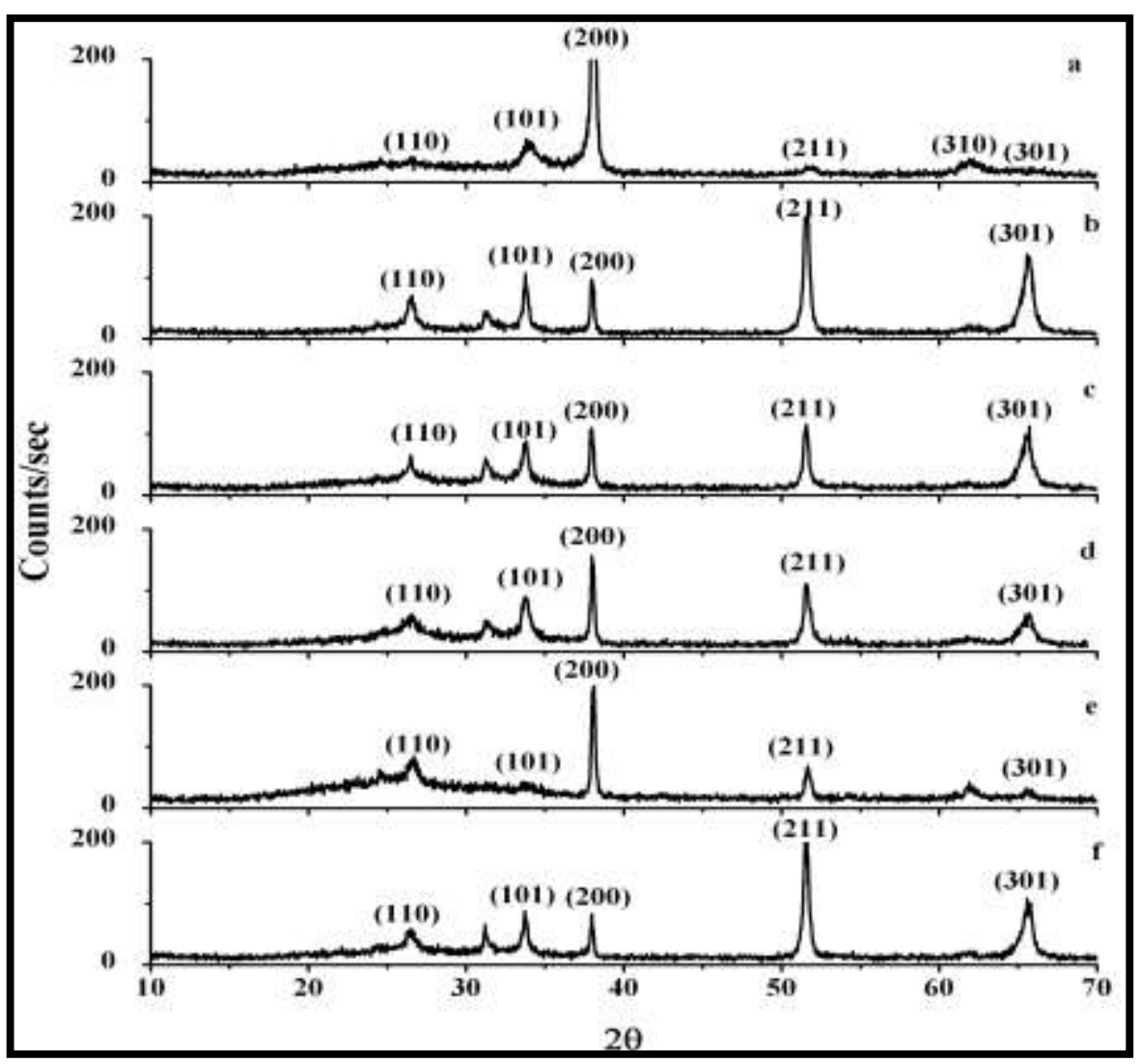

Fig. (2): XRD patterns for $0.8 \mathrm{M} \mathrm{SnO}_{2}: \mathrm{F}$ (a) $0 \% \mathrm{~F}$, (b) $5 \% \mathrm{~F}$, (c) $10 \% \mathrm{~F}$, (d) $15 \% \mathrm{~F}$, (e) $20 \% \mathrm{~F}$, (f) $25 \% \mathrm{~F}$ 
As fluorine incorporation proceeds from $(5 \% \mathrm{~F})$ in the tin oxide film, Fig.(2,b-f) the intensity of (110),(101), (211) and (301) planes increase simultaneously with significant decrease in (200) plane. The (211) \& (301) planes exhibit low intensity in pure sample and show considerable increase as fluorine atoms are incorporated. Those same planes exhibit gradual decrease with increasing fluorine concentration up to $20 \% \mathrm{~F}$. The observed dramatic decrease in the intensity of (200) may be due to the replacement of oxygen atoms by $\mathrm{F}$ atom which gradually tends to be in interstitial position in $\mathrm{SnO}_{2}$ lattice. Therefore, the lower intensity of (110), (101), (211) \& (301) peaks in conjunction with the relatively higher intensity (200) in XRD pattern of samples incorporated with $20 \% \mathrm{~F}$ could be considered as a good evidence for the nearly complete accommodation of fluorine atoms in oxygen vacancies and bonded oxygen and some of fluorine atoms are in interstitial position. The approximate similarity between XRD patterns for pure sample with those for the incorporated sample with $20 \% \mathrm{~F}$, favor the equilibrium state in $\mathrm{SnO}_{2}$ lattice which is then violated by the higher increase of fluorine incorporation $(25 \%)$. Since the charge on fluorine ion is only half that of the charge on the oxygen ion, the coulomb forces that bind the lattice together are reduced. Therefore, it is anticipated that the higher increase of incorporated fluorine will destroy the equilibrium of the $\mathrm{SnO}_{2}$ lattice and generate oxygen vacancies. This conjecture is backed up by the high intensity of (211) and (301) in conjunction with the lower intensity of (200). This may be due to the substitution of fluorine in new generated oxygen vacancies and bonded oxygen as shown in XRD of incorporated sample with $25 \% \mathrm{~F}$ which is nearly similar to that of $5 \% \mathrm{~F}$ samples.

There is a consensus about the decrease or increase of the peak intensity in pure tin oxide when fluorine is incorporated but there is no agreement which of the peaks systematically increases or decreases as a function of fluorine concentration [15]. At higher fluorine doping about 40\%, only the (200) peak with lower intensity is seen, while other peaks are not observed [4 \&10].

The crystallite size for the investigated samples is calculated from XRD patterns using Scherer formula, FWHM values corrected for the instrumental broadening. The change in crystallite size between 20 and $40 \mathrm{~nm}$ as a function of fluorine concentration is shown in Fig.(3). 


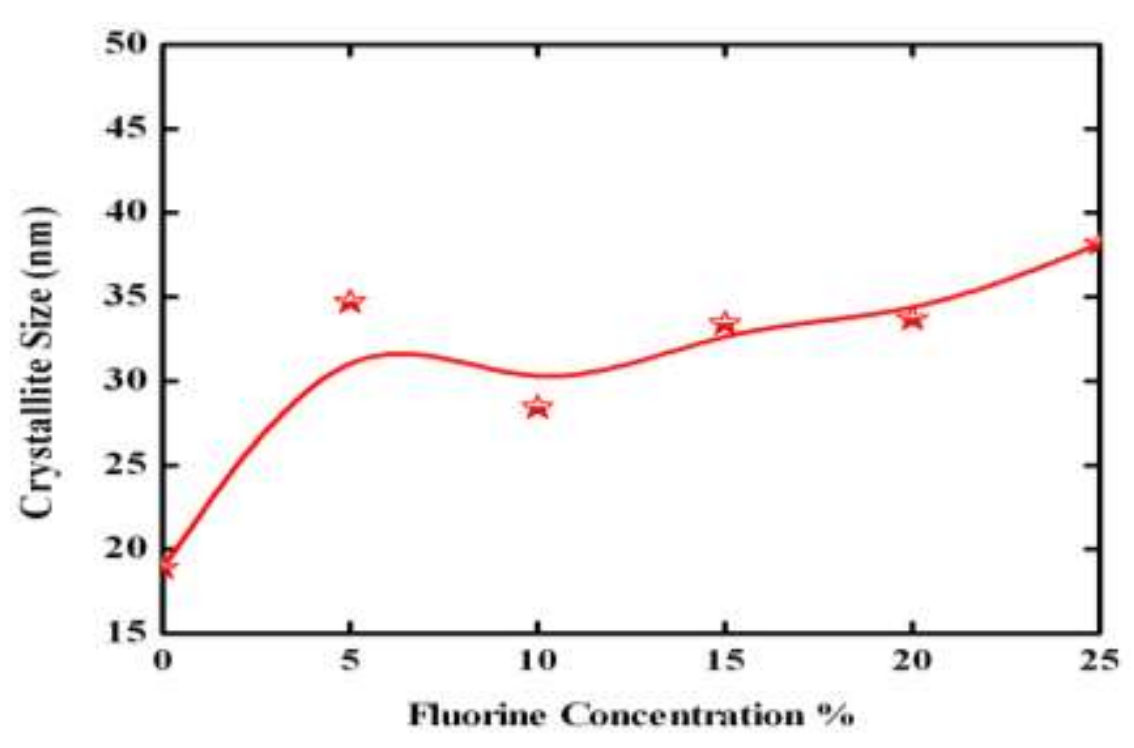

Fig. (3): The crystallite size as function of fluorine concentrations for $\mathrm{SnO}_{2}$ : $\mathrm{F}$ samples.

\subsection{Morphological Properties:}

To get more details about roughness and microstructure of the investigated samples, AFM was employed. Two -and three - dimensional atomic force microscopy (AFM) images for pure and incorporated $\mathrm{SnO}_{2}$ samples with different concentrations of fluorine are displayed in Fig. (4 \& 5).

The RMS roughness extracted from the AFM images Fig. (4) \& Fig. (5) as a function of fluorine concentration are given in Table (1). It is seen from the Table (1) and Fig. (4) \& Fig.(5) that the pure film has lower roughness than that of incorporated ones, up to $15 \% \mathrm{~F}$. The 2-D AFM image for pure sample Fig. (4 -a) shows compact and homogenous small grains. Some of these grains are clustered cauliflower-like shape with well defined boundaries while the others are without border (independent). The 3-D image shows homogenous grains with clear facets and sharp heights. The small size and homogeneity of the grains stem from the preferred orientation (200) growth as explained in XRD earlier. 
$\mathbf{a}$
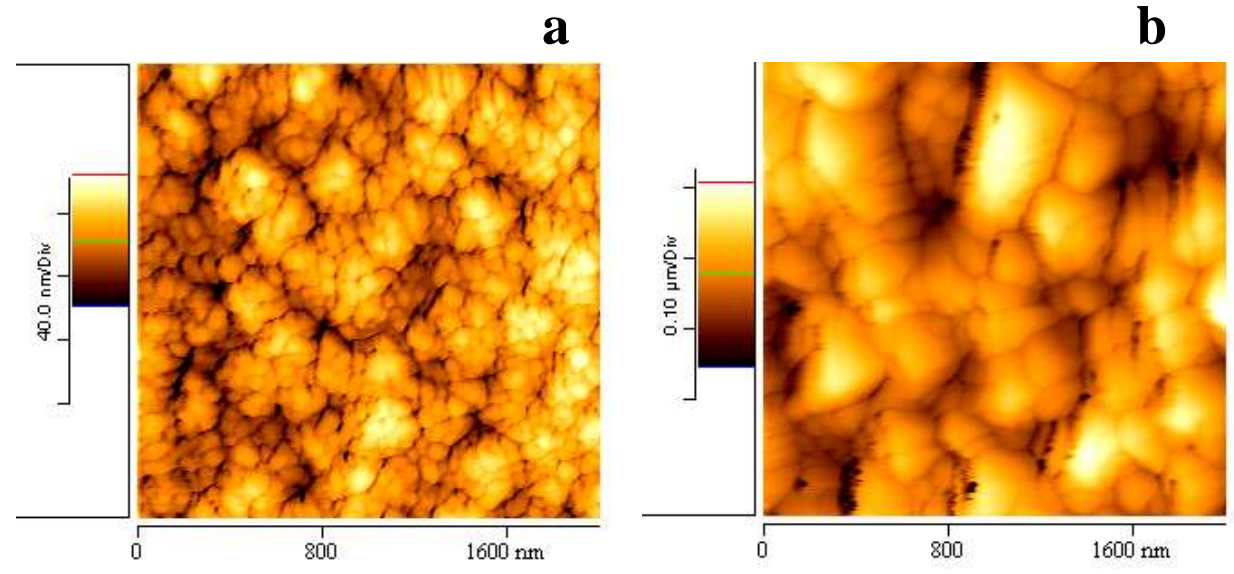

c
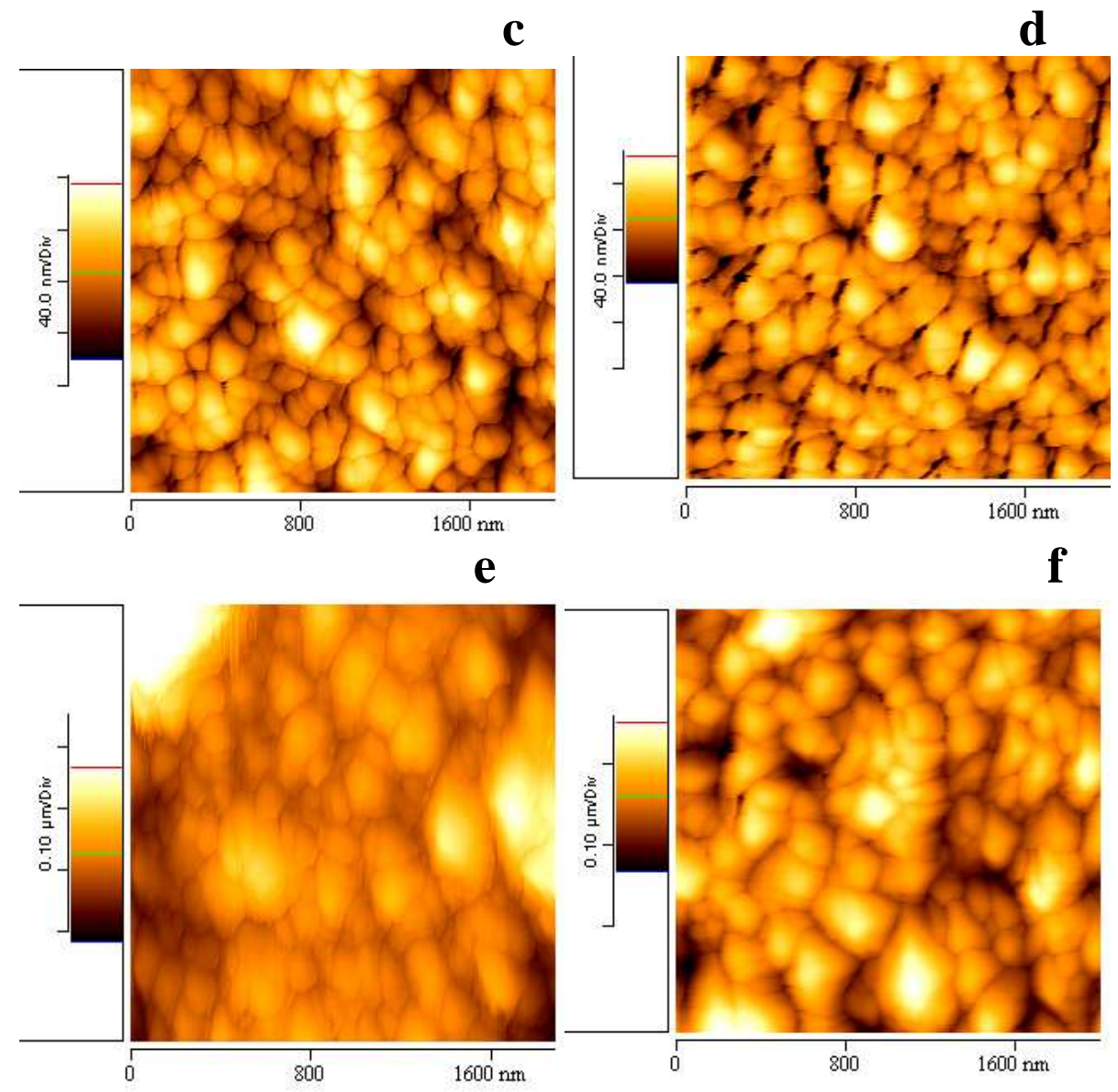

Fig.(4): The 2-D AFM image for $0.8 \mathrm{M} \mathrm{SnO}_{2}: \mathrm{F}$ (a) $0 \% \mathrm{~F}$, (b) $5 \% \mathrm{~F}$, (c) $10 \% \mathrm{~F}$, (d) $15 \% \mathrm{~F}$, (e) $20 \% \mathrm{~F}$, (f) $25 \% \mathrm{~F}$ 

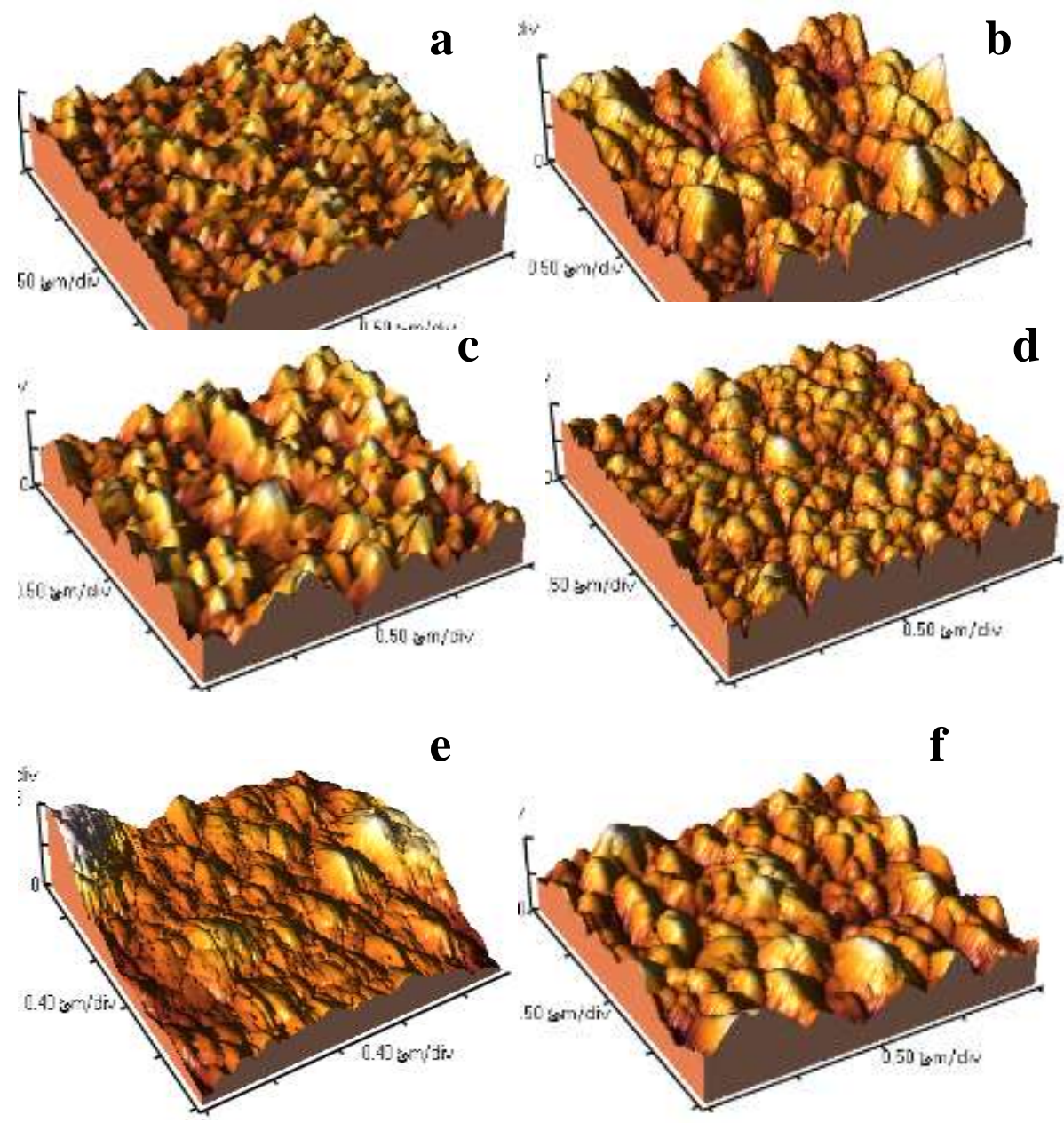

Fig. (5): The 3-D AFM image for $0.8 \mathrm{M} \mathrm{SnO}_{2}: \mathrm{F}$ (a) $0 \% \mathrm{~F}$, (b) $5 \% \mathrm{~F}$, (c) $10 \% \mathrm{~F}$, (d) $15 \% \mathrm{~F}$, (e) $20 \% \mathrm{~F}$, (f) $25 \% \mathrm{~F}$

The AFM 2-D image for sample incorporated 5\% F Fig. (4-b) has the highest roughness and shows random and nonhomogenous distribution of grains. Smaller grains in between bigger grains are apparent, which may be due to the growth enhancement of clusters and independent grains, in pure sample, by the incorporated fluorine. The big and small grains could be discriminated since they seem protruding from the surface as shown in $3 \mathrm{D}$-image (Fig.5b). As fluorine concentration increase from $5 \%$ up to $15 \%$ the surface roughness decreases and the grains are more regular in size and look more uniform and tend to have an oval shape and oriented in one direction. As depicted in 2-D images Fig. (4). The sample incorporated $20 \% \mathrm{~F}$ and $25 \% \mathrm{~F}$ show elongated grains and higher roughness which suggests inhomogeneous growth. 
It is could be concluded that the incorporation of fluorine in $\mathrm{SnO}_{2}$ lattice induces changes in grain shape and size which correspond to changes in roughness, and changes in intensity and preferred orientation in some planes in the XRD pattern.

Table (1): The RMS roughness as a function of fluorine concentration for $(0.8$ M) $\mathrm{SnO}_{2}: \mathrm{F}$

\begin{tabular}{||c|c|c|c||}
\hline F \% & $\begin{array}{c}\text { RMS Rough (Rq) } \\
\text { Ver. (nm) }\end{array}$ & $\begin{array}{c}\text { RMS Rough (Rq) } \\
\text { Hori. (nm) }\end{array}$ & $\begin{array}{c}\text { RMS Rough (Rq) area.z } \\
\text { (nm) }\end{array}$ \\
\hline 0 & 11.70 & 14.12 & 14.07 \\
\hline 5 & 39.27 & 31.85 & 44.23 \\
\hline \hline 10 & 21.70 & 22.87 & 22.73 \\
\hline 15 & 18.77 & 16.88 & 18.64 \\
\hline 20 & 38.08 & 35.00 & 47.10 \\
\hline 25 & 31.05 & 34.40 & 30.56 \\
\hline
\end{tabular}

\subsection{Optical properties}

The measured specular transmittance and reflectance spectra in the wavelength range 0.2 to $2.5 \mu \mathrm{m}$ for pure and fluorine incorporated tin oxide are presented in Fig.(6).

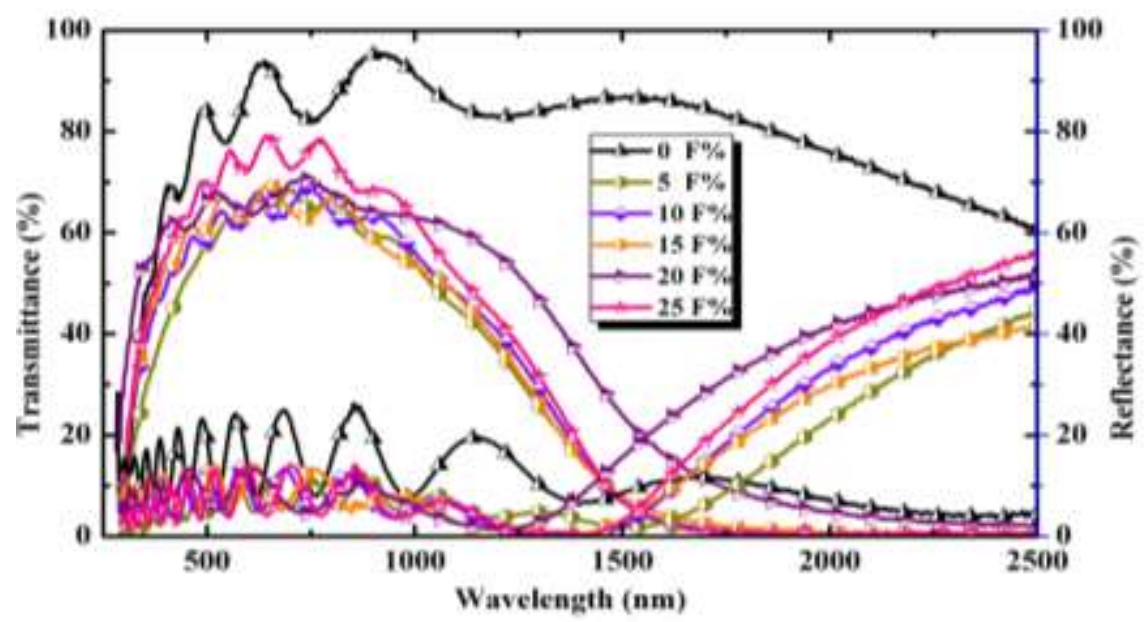

Fig. (6): Measured transmittance and reflectance spectra for $0.8 \mathrm{M} \mathrm{SnO}_{2}: \mathrm{F}$ 
The observed sharp absorption edge for pure and incorporated samples in the shorter wavelength region of $\mathrm{T}-\lambda$ curve assumes allowed direct transition from the top of the valence band to the bottom of the conduction band.

To obtain the energy gap $\mathrm{E}_{\mathrm{g}}$ we plotted the graph between $(\alpha \mathrm{hu})^{2}$ and hu according to the formula of direct band gap [16]

$$
\alpha h v=A\left(h v-E_{g}\right)^{1 / 2}
$$

The energy gap $\mathrm{E}_{\mathrm{g}}$ was determined by extrapolating the linear part of the curve $(\alpha h v)^{2}$ versus hu to intercept hu axis at $(\alpha h v)^{2}=0$. The value of $E_{g}$ for pure sample was found to be $(3.72 \mathrm{eV})$ which is greater than the reported value $3.2 \mathrm{eV}$ [10] for samples with submicron crystallite size. This difference could be attributed to quantum size effect since the crystallite size of the investigated sample is $\sim 18 \mathrm{~nm}$ as revealed by XRD. The values $\mathrm{E}_{\mathrm{g}}$ for incorporated samples is given in Table (2). The change in $\mathrm{E}_{\mathrm{g}}(3.72-3.86 \mathrm{eV})$ due to fluorine incorporation may be attributed to Moss- Burstein (M-B) shift [17, 18]. Fluorine atom behaves as a donor if it replaces the oxygen atom until it acts as an acceptor when it goes in interstitial positions, in $\mathrm{SnO}_{2}$ lattice. This means that the free carrier concentration, which affects the (M- B) shift, depends on the position of fluorine atom. The obtained results are in agreement with that reported [10].

The doped samples are of the same thickness, due to fixation of preparation conditions, then the variation in transmittance and reflectance are then mainly related to the concentration of incorporated fluorine in the film. In the visible region, the pure sample has high transmittance $\sim 90 \%$ while the incorporated samples have relatively lower transmittance $\sim 70 \%$. The reflectance values of pure and incorporated sample are close to (12\%). In near infrared (NIR) region, the $\mathrm{T}-\lambda$ curve is characterized by an observable high absorption, its level depends mainly on the free carrier concentration which originates from nonstoichiometry and incorporated fluorine atoms. The plasma edge $\left(\lambda_{\mathrm{p}}\right)$ could be estimated reliably from the intercept of the extrapolated linear portion of $\mathrm{T}-\lambda$ curve with $\lambda$ axis Fig.(6). It is found to shift to shorter wavelengths as the flourine concentration increases.

It is clear from Fig.(6) that $\lambda_{p}$, the plasma edge is nearly the same for samples incorporated with $5 \%$ up to $25 \% \mathrm{~F}$ except the sample incorporated 20 $\% \mathrm{~F}$ which shows higher $\lambda_{\mathrm{p}}$. This may be explained by the substitution of $\mathrm{O}_{2}$ by fluorine atom is predominant in the samples. As for the samples doped $20 \% \mathrm{~F}$ the fluorine goes interstitially. The plasma frequency $\omega_{\mathrm{p}}$ could then be 
considered as a monitor for tracing the accommodation of fluorine atom in $\mathrm{SnO}_{2}$ lattice. $\lambda_{\mathrm{p}}$ shifts to shorter wavelength when substitution of fluorine is predominant and shifts to longer wavelength when the interstitial fluorine prevails. The XRD patterns of the samples are compatible with these results. The plasma frequency is used for calculating some parameters such as the free carrier concentration, mobility, Fermi energy and mean free path.

The carrier concentration $(\mathrm{N})$ is calculated from [19]

$$
\omega_{p}=\frac{2 \pi \mathrm{c}}{\lambda_{p}}=\sqrt{\frac{\mathrm{N}^{2}}{\varepsilon_{\circ} \varepsilon_{\infty} \mathrm{m}_{\circ}^{*}}}
$$

where $\boldsymbol{\varepsilon}_{\infty}$ and $\boldsymbol{\varepsilon}_{\circ}$ represent the high frequency and free space dielectric constants, respectively, $\mathrm{m}_{0} *$ is the effective mass of the charge carriers. Here substituting $\varepsilon_{\infty}=4$ and $m_{0}{ }^{*}=0.3 m_{0}[20], N$ is the carrier concentration and $\lambda_{\mathrm{p}}$ is the plasma wavelength.

Also, the Fermi level is calculated from [21].

$$
\mathrm{E}_{\mathrm{f}}=\left(\frac{\hbar^{2}}{8 \mathrm{~m}^{*}}\right)\left(\frac{3 \mathrm{~N}}{\pi}\right)^{\frac{2}{3}}
$$

where $\mathrm{m}^{*}$ is the effective mass $=0.3 \mathrm{~m}_{0}[20]$ and $\mathrm{N}$ is the calculated carrier concentration.

The mobility is also calculated from [4]

$$
\mu_{\mathrm{i}}=\sqrt{\frac{2}{\mathrm{~m}^{*}}}\left(\frac{\varepsilon^{2} \mathrm{E}_{f}^{2} / 3}{\pi e^{2} \mathrm{f}(\mathrm{x}) \mathrm{N}}\right)
$$

where $\varepsilon$ is the high frequency dielectric constant, $\mathrm{m} *$ the effective mass $=0.3$ $\mathrm{m}_{0}, \mathrm{E}_{\mathrm{f}}$ is the Fermi energy at room temperature, $\mathrm{N}$ is the free carrier concentration.

The mean free path of the free carrier is then estimated using the relation [22].

$$
l=\left(\frac{\mathrm{h}}{2 \mathrm{e}}\right) \cdot\left(\sqrt[3]{\frac{3 \mathrm{~N}}{\pi}}\right) \cdot \mu
$$

The calculated values of $\left(E_{g}, \mu, N, E_{f}, 1, \sigma, \rho\right)$ from optical transmittance of the investigate samples of $\mathrm{SnO}_{2}: \mathrm{F}$ as a function of fluorine concentration in 
spray solution are given in Table (2). The pure sample shows that $\lambda_{\mathrm{p}}$ is out of the measuring range, 200 to $2500 \mathrm{~nm}$. The calculated carrier concentration for the incorporated samples is $\left(5.35 \times 10^{21}\right.$ to $\left.5.81 \times 10^{21} \mathrm{Cm}^{-3}\right)$. The free carrier concentration for the pure sample calculated according to (2) would be too low and may be less than $10^{19} / \mathrm{cm}^{3}$, since $\lambda_{\mathrm{p}}$ is out of the measuring range.

The slight change in $\mathrm{N}$ for incorporated samples may be due to the competition between substitution and interstitial processes of fluorine atom.

The values of $\mathrm{E}_{\mathrm{f}}$ given in Table(2) are in agreement with that reported $[4,12]$ and could be considered as an indication for the degeneracy of the investigated samples. The fluorine donor electron states hybridizes with tin oxide host conduction band at energies about $1.4-2.0 \mathrm{eV}$ above the lowest conduction band which is populated by the free carriers of $\mathrm{N}=3.9 \times 10^{20} \mathrm{~cm}^{-3}$

Table (2): Optical and Electrical parameters for (0.8M) $\mathrm{SnO}_{2}: \mathrm{F}$

\begin{tabular}{|c|c|c|c|c|c|c|c|c|c|c|}
\hline F \% & $\begin{array}{c}\mathrm{N} \times 10^{21} \\
\left(\mathrm{~cm}^{-3}\right)\end{array}$ & $\begin{array}{c}\mathrm{E}_{\mathrm{f}} \\
(\mathrm{eV})\end{array}$ & $\begin{array}{c}\mu_{\mathrm{cal}} \\
\left(\mathrm{cm}^{2} /\right. \\
\mathrm{V} . \mathrm{s})\end{array}$ & $\begin{array}{c}\lambda_{\mathrm{p}} \\
(\mathrm{nm})\end{array}$ & $\begin{array}{c}\rho_{\text {opt. }} \\
\times 10^{-4} \\
(\Omega . c m) \\
\end{array}$ & $\begin{array}{c}\mathrm{t} \\
(\mathrm{nm})\end{array}$ & $\begin{array}{c}E_{g} \\
(\mathrm{eV})\end{array}$ & $\begin{array}{c}\mathrm{R} \square \\
(\Omega \square)\end{array}$ & $\mathrm{L}(\mathrm{nm})$ & $\begin{array}{c}\text { } \rho_{\text {elec. }} \\
\times 10^{-4} \\
(\Omega . \mathrm{cm})\end{array}$ \\
\hline 0 & $\ldots$ & $\ldots$ & - & - & $\ldots$ & 418 & 3.72 & 40 & 0.5 & 0.16 \\
\hline 5 & 5.35 & 2.38 & 1.41 & 1580 & 6.03 & 789 & 3.78 & 3 & 0.46 & 2.37 \\
\hline 10 & 5.66 & 2.48 & 1.28 & 1536 & 5.70 & 494 & 3.8 & 9 & 0.44 & 4.45 \\
\hline 15 & 5.63 & 2.47 & 1.23 & 1540 & 5.73 & 392 & 3.82 & 14 & 0.43 & 5.49 \\
\hline 20 & 5.60 & 2.47 & 1.20 & 1544 & 5.76 & 177 & 3.83 & 9 & 0.44 & 1.60 \\
\hline 25 & 5.81 & 2.53 & 1.22 & 1516 & 5.56 & 474 & 3.86 & 6 & 0.50 & 2.85 \\
\hline
\end{tabular}

\subsection{Sheet Resistance $R \square$ :}

It is essential to evaluate the performance of the prepared material as TCO films. Sheet resistance $\mathrm{R} \square$ is a useful parameter in comparing thin films, particularly those of the same material deposited under different conditions. The measured $\mathrm{R}_{\square}$ values for the samples are traced as a function of $F$ concentration with the reflectance in IR region $(\lambda=2.5 \mu \mathrm{m})$ on the same Fig. (7) to clarify the variation of one relative to the other. It is clear that the decrease in $\mathrm{R}_{\square}$ corresponds to an increase in reflectance which may be due to the increase in number of free carriers (electrons). 


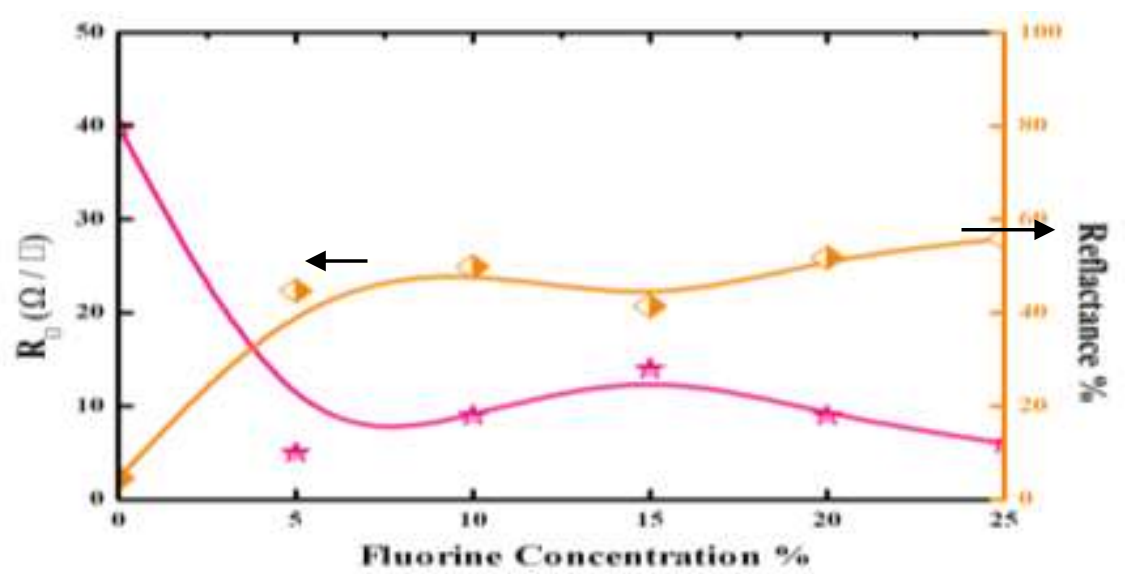

Fig. (7): Change in the Sheet Resistance and Reflectance \% at $2500 \mathrm{~nm}$ as a function of fluorine concentration

When fluorine $(\mathrm{F})$ is incorporated in tin oxide films, each $\mathrm{F}^{1-}$ anion may substitute an $\mathrm{O}^{2-}$ anion in the lattice and introduces more free electrons [23]. This results confirm the increase of free electrons and hence decreases the value of $R_{\text {sh. }}$.

\subsection{Figure of merit $\phi$}

The figure of merit $\phi$ has been a common rating method for TCO films for their possible use in solar cell applications. The device performance is determined from $\phi[23]$ :

$$
\phi=\frac{\mathrm{T}^{10}}{\mathrm{R}_{\square}}
$$

where $T$ is the transmittance at $\lambda=550 \mathrm{~nm}$ and $R_{\square}$ is the sheet resistance.

Also, a performance coefficient (PC) formula is [24]:

$$
P C=\frac{T_{V I S} R_{N I R}}{T_{N I R} R_{V I S}+0.01}
$$

where $\mathrm{T}_{\mathrm{VIS}}, \mathrm{T}_{\mathrm{NIR}}, \mathrm{R}_{\mathrm{VIS}}$ and $\mathrm{R}_{\mathrm{NIR}}$ are the transmittance and reflectance in visible and NIR regions. 
The calculated values for Figure of merit $\Phi$ and the performance coefficient PC for the investigated samples of $\mathrm{SnO}_{2}: \mathrm{F}$ are summarized in Table (3).

Table (3): The values of Figure of Merit $\Phi$ and the Performance Coefficient PC of $\mathrm{SnO}_{2}$ as a function of fluorine concentration:

\begin{tabular}{|l|l|l|l|l|l|l|l|}
\hline $\mathbf{F}$ & $\begin{array}{c}\mathbf{R}_{\square} \\
\left(\mathbf{\Omega} / \mathbf{c m}^{2}\right)\end{array}$ & $\begin{array}{c}\mathbf{T}(\mathbf{7 5 0}) \\
\mathbf{\%}\end{array}$ & $\begin{array}{c}\mathbf{T}(\mathbf{2 5 0 0}) \\
\mathbf{\%}\end{array}$ & $\begin{array}{c}\mathbf{R}(\mathbf{7 5 0}) \\
\mathbf{\%}\end{array}$ & $\begin{array}{c}\mathbf{R}(\mathbf{2 5 0 0}) \\
\mathbf{\%}\end{array}$ & $\mathbf{\Phi}\left(\Omega^{-1}\right)$ & $\mathbf{P C}$ \\
\hline 0 & 40 & 95.292 & 60.14 & 8.79 & 4.583 & $1.54 \mathrm{E}-02$ & 0.695 \\
\hline 5 & 3 & 65.128 & 0.598 & 11.4 & 44.789 & $4.58 \mathrm{E}-03$ & 27.3 \\
\hline 10 & 9 & 68.669 & 0.553 & 4.88 & 49.913 & $2.59 \mathrm{E}-03$ & 33.4 \\
\hline 15 & 14 & 63.362 & 0.54 & 1.31 & 41.431 & $7.45 \mathrm{E}-04$ & 24.5 \\
\hline 20 & 9 & 70.467 & 1.782 & 4.71 & 51.839 & $3.35 \mathrm{E}-03$ & 33.7 \\
\hline 25 & 6 & 62.329 & 0.589 & 6.54 & 55.96 & $1.47 \mathrm{E}-03$ & 33.6 \\
\hline
\end{tabular}

The obtained values of $\Phi \& \mathrm{PC}$ for the investigated $\mathrm{SnO}_{2}$ : $\mathrm{F}$ samples indicate that this is a cheap and easy to prepare material, may be promising and has potential applications in solar energy, heat mirror and optoelectronic devices.

\section{References:}

1. J.P.Upadhyay, S.R.Vishwakarma and H.C.Prasad, Thin Solid Films, 169, 195 (1989).

2. A.K.Abass, H.Bakr, S.A.Jassim and T.A.Fahad, Solar Energy Mater.17, 425 (1988).

3. R. Asomoza, A. Maldonado, J. Rickards, E.P. Zironi, M.H. Farias, L. Cota-Araiza, G. Soto, Thin Solid Films, 203, 195 (1991).

4. A.V. Moholkar, S.M. Pawar, K.Y. Rajpure, C.H. Bhosale, J.H. Kim, Applied Surface Science 255, 9358 (2009).

5. H.H.Afify, R.S.Momtaz, W.A. Badawi, and S.A.Nasser, J. Materials Science: Materials in Electronics, 2, 40 (1990).

6. H.H. Afify, F.S. Terra \& R.S.Momtaz, J. Materials Science: Materials in Electronics 7, 149 (1996).

7. H.H. Afify, S.A.Mahmoud \& A.Ashour, Thin Solid Films, 263, 248 (1995).

8. Kodigala Subba Ramaiah, V. Sundara Raja, Applied Surface Science, 253, 1451 (2006).

9. Chitra Agashe, M.G.Takwale, and V.G.Bhide, J. Appl. Phys., 70, 7382 (1991)

10. C.Agashe, S. S. Major, J. Materials Science, 31, 2965 (1996). 
11. Carla D. Canestraro, Marcela M. Oliveira, Roge' rio Valaski, Marcus V.S. da Silva, Denis G.F. David, Iuri Pepe, Antonio Ferreira da Silva, Lucimara S. Roman, Clas Persson, Applied Surface Science, 255, 1874 (2008).

12. E. Elangovan, K. Ramamurthi, Thin Solid Films, 476, 231 (2005).

13. D. Zaouk, R. Al Asmar, J. Podlecki, Y. Zaatar, A. Khoury, A. Foucaran, Microelectronics Journal, 38, 884 (2007).

14. M. Fantini, I. Torriani, Thin Solid Films, 138, 255 (1986).

15. C.Agashe, S. S. Major J. Materials Science Letters, 15, 497 (1996).

16. A.A.Ramadan, A.A.Abdl El - Mongy, A.M.El-Shabiny, A.T.Mater, S.H.Mostafa, E.A.El- Sheheedy, and H.M.Hashem, Cryst. Res. Technol. 44, 111 (2009).

17. A. Aqili, A. Maqsood, Applied Optics, 41, 219 (2002).

18. G.K. Mor, K. Shankar, M. Paulose, O.K. Varghese, C.A. Grimes, Appl. Phys. Lett. 91, 152111 (2007).

19. S.H. Wemple, J.A. Seman, Appl. Optics, 12, 2947 (1973).

20. B. Thangaraju, Thin Solid Films, 402, 71 (2002).

21. E.Shanthi, A. Banerjee, V.Dutta, K.L.Chopra, J. Appl Phys., 53, 1615 (1982).

22. T. Minami, S. Takata, H. Sato, H. Sonohara, J. Vac. Sci. Technol. A,Vac. Surf. Films, 13, 1095 (1995)

23. R.G. Gordon, MRS Bull. 25, 52 (2000).

24. G.Haake, J. Appl. Phys., 47, 4086 (1976).

25. H.M. Hashem, Ph.D. Thesis, Physical Department, Helwan University, egypt. (2008). 